\title{
Development of a GIS-based platform for the allocation and optimisation of distributed storage in urban energy systems ${ }^{\text {th }}$
}

\author{
Alaa Alhamwi*, Wided Medjroubi, Thomas Vogt, Carsten Agert* \\ DLR Institute of Networked Energy Systems, Grid and System Modelling Group, Carl-von-Ossietzky-Str.15, 26129 Oldenburg, Germany
}

\begin{abstract}
As the world is already highly urbanised, energy systems in cities are already responsible for significant amount of the global Greenhouse Gas (GHG) emissions. Therefore, climate change mitigation demands a fundamental transformation in the urban energy systems (UES), energy markets and energy policies. In this context, the large shift to micro-generation from renewable energy sources and their integration in the current energy system are a technical challenge for future energy systems design and operation. This will be further exacerbated if flexibilisation technologies such as storage are not efficiently integrated. For this purpose, an accurate modelling and representation of Urban Energy Systems requires the characterisation of different urban energy requirements. These requirements, along with the urban fabric of cities, should be adequately incorporated in a spatial-temporal framework including both static and dynamic datasets. In this context, urban energy models provide policymakers with qualitative and quantitative insights for the planing of future UES. Within this framework, urban energy models integrated in Geographic Information Systems (GIS) will play an important role due to their multi-layer approach.
\end{abstract}

This study introduces an open source GIS-based platform called FlexiGIS for the optimisation of urban energy systems. FlexiGIS is used in this contribution to optimally allocate distributed battery storage in urban areas. The FlexiGIS platform provides the urban energy infrastructure (spatial dimension), simulates electricity consumption and generation (spatial and temporal dimension) and performs a linear optimisation for the economic deployment of micro-generation and decentralised storage under different energy scenarios. The first study case considers the city as a single system or energy cell, while the second one assumes that the city is divided into connected subsystems or districts. The total UES costs and required storage capacities for the investigated scenarios are obtained using optimisation. A key finding is that, for the scenarios investigated, investing in local electricity storage and renewable power generation can significantly reduce the total system costs and increase urban self-sufficiency. This study also highlights that the off-grid scenario (isolated city) is not an optimal choice.

Keywords:

Urban Energy Systems (UES), Geographic Information Systems (GIS), OpenStreetMap (OSM), open source data, flexibility options, FlexiGIS platform

\section{Introduction}

The massive surge of global urbanisation is among the biggest global challenges in the $21^{\text {st }}$ century $[2,3,4]$. In the next three decades, the world's population in cities is projected to increase from just 4 billions today to almost 7 billions by $2050[5,6]$. Therefore, it is expected that, a significant amount of new urban infrastructure including new housing and energy facilities will be added in the coming years. This means that, cities will be facing tremendous challenges concerning in particular energy consumption. Cities already consume about $70 \%$ of the total global energy, which accounts for more than two thirds of the world's $\mathrm{CO}_{2}$ emissions [2,3]. In order to efficiently

\footnotetext{
The short version of the paper was presented at CUE2018, Jun 5-7, Shanghai, China. This paper is a substantial extension of the short version of the conference paper [1].

${ }^{*}$ Corresponding author

Email address: alaa.alhamwi@dlr.de (Alaa Alhamwi)
}

plan new infrastructure for Urban Energy System (UES), new modelling techniques are needed. An example is that, planning the required infrastructure in developing countries using same old techniques has a $\mathrm{CO}_{2}$ footprint similar to that of the current infrastructure in developed countries. This means that, the expansion of emerging urban infrastructures in developing countries could emit $350 \mathrm{Gt}$ of $\mathrm{CO}_{2}$ emissions [7] when using old techniques.

On the other hand, future planing of urban areas can be used to mitigate the global warming effects. This has been recently acknowledged in different agreements such as the New Urban Agenda [8] and the Paris Agreement [9]. However, planing and implementation strategies pursuing sustainability principles in urban area are still missing [10]. It is therefore important to identify plausible policies and suitable energy scenarios to ensure a systematic decarbonisation of urban energy infrastructure [11]. In this context, energy modelling can guide policy to tackle those challenges and help achieve public acceptance 
in particular in the context of renewable energy sources (RES) integration.

Table 1 introduces an overview of energy models at various urban levels. Most of the models are built for a specific aspect. For example, [12] aims to model the embodied energy in urban materials, the flows of wastes and water and their dependence on the environment in cities. The authors in [13] focused on integrating machine learning algorithm with engineering simulation to understand the impact of buildings consumption on multiple temporal scales. In addition, those models do not cover all perspectives of energy usage in urban areas limiting their ability to address relevant future UES challenges. Furthermore, the development of smart cities requires a local perspective taking the geographical context into account $[14,10]$. Within this framework, USE integrated in Geographic Information Systems (GIS) offer many advantages allowing a multi-layer representation. Previous contributions addressed the simulation of flexibilisation technologies using Geographic Information Systems (GIS). For instance, a GIS-based method for modelling urban heat requirement integrating energy conversion systems like Combined Heat and Power (CHP) was developed in [15]. The authors in [16] used GIS to estimate the theoretical potential of Demand Side Management (DSM) from heating and ventilation air conditioning (HVAC) in commercial buildings. Other contributions focused mainly on the transportation sector like in [17], where the authors investigated the integration of Electric Vehicles (EVs) and its charging infrastructure using GIS.

Based on a comprehensive overview of GIS-based UES models in [23], a gap in the academic literature related to the optimisation of flexibility options (e.g. electricity storage) was identified. This led to the development of the FlexiGIS model by the authors of this contribution. FlexiGIS aims at exploring the impact of new RES and storage technologies in cities using publicly available datasets. In this contribution the authors explore storage as an emerging technology which will contribute to accelerate the deployment of RES. This goal is achieved by investigating the impact of storage on the operation, costs and planning of future UES using the FlexiGIS model. This work contributes to linking the FlexiGIS platform to real-world applications.

The originality of the present work lies in two main points. First, the integration of GIS techniques to calculate the optimal size, location and operation of electricity battery storage. Second, the open source and open data approach pursued here. The present contribution is structured as follows: a short overview of the FlexiGIS platform is introduced in section 2, the potential estimation of urban electricity datasets are presented in Section 3. FlexiGIS is applied for the city of Oldenburg in Section 4 for different scenarios including: Reference, Islanded, RES-Mix and Future scenarios. A linear optimisation is performed to investigate the different scenarios. The results and discussion of the optimisation for each scenario are presented in Section 5. Finally, Section 7 highlights the main findings and conclusions of this contribution.

\section{The FlexiGIS platform}

FlexiGIS stands for Flexibilisation in Geographic Information System. It establishes the underlying urban energy infrastructure, simulates urban energy requirements (including energy generation and consumption) and performs a cost optimisation of the required storage. One the of the goals of FlexiGIS is to assess self-consumption in cities and the maximisation of RES integration in urban settings at minimal system costs. Figure 1 illustrates the structure of the FlexiGIS platform, which contains the following elements:

- Module I: Setting-up urban energy infrastructure: by extracting, pre-processing, filtering and clustering the UES infrastructure datasets such as buildings, roads and installed renewable power capacities (e.g. Figure 2) for a specific region/urban settlement. More details are available in [23].

- Module II: Modelling urban energy requirements: This module complements the previous one by adding the temporal dimension. It simulates local electricity consumption and on-site renewable power generation and links them to the underlying urban infrastructure. The results of this step were successfully validated against measured data ([24]).

- Module III: Optimisation of storage costs and capacities: here the optimisation of storage is conducted by integrating the urbs model in the FlexiGIS platform and using the datasets collected in the previous two modules. Different energy scenarios for deploying energy storage and renewables in cities can be implemented and investigated. This module is the newest development of the FlexiGIS platform.

As shown in figure 1, all modules are connected to each other by means of an interactive database that is used by the entire platform. The modules data outputs can be visualised as single or muliple layers using GIS desktop software such as the open source QGIS tool [25].

In this contribution, the goal of the optimisation is to match the local electricity demand by allowing storage construction with the least total cost at the urban level (building, district or city). The storage size and operation will be cost-optimised. This is achieved by using the FlexiGIS platform [23] combined with the open source urbs model [26, 27]. The next section provides an overview of the urbs tool.

\section{urbs model}

urbs is an open source free toolbox for capacity expansion in energy systems developed at the Technical University of $\mathrm{Mu}-$ nich [26]. It is licensed under the "GNU General Public License" and provides an extendable tool for investigating energy scenarios. The urbs tools encompasses the following entities: 
Table 1: List of existing urban energy system models included in the overview

\begin{tabular}{|c|c|c|c|}
\hline Model & Full Name & Main Focus & Reference \\
\hline CitySim & $\begin{array}{l}\text { Micro-Simulation of Resource Flows } \\
\text { for Sustainable Urban Planning }\end{array}$ & $\begin{array}{l}\text { simulate and optimise building-related re- } \\
\text { source flows }\end{array}$ & {$[12]$} \\
\hline DUE-S & Data-driven Urban Energy Simulation & $\begin{array}{l}\text { predicts energy consumption at multi-scale ur- } \\
\text { ban energy modelling workflow }\end{array}$ & [13] \\
\hline SynCity & $\begin{array}{l}\text { Synthetic City: A tool kit for urban en- } \\
\text { ergy system modelling }\end{array}$ & $\begin{array}{l}\text { facilitates the integrated modelling of urban } \\
\text { energy systems }\end{array}$ & {$[18]$} \\
\hline SUNtool & $\begin{array}{l}\text { Sustainable Urban Neighbourhood } \\
\text { modelling tool }\end{array}$ & $\begin{array}{l}\text { supports urban planners to optimise the sus- } \\
\text { tainability of urban neighbourhoods }\end{array}$ & [19] \\
\hline HUES & Holistic Urban Energy Simulation & $\begin{array}{l}\text { explores the relationship between district size } \\
\text { and the sizing of the necessary infrastructure }\end{array}$ & [20] \\
\hline CityGML & $\begin{array}{l}\text { Standardised data model to store digital } \\
\text { 3D models of cities }\end{array}$ & $\begin{array}{l}\text { multi-purpose and multi-scale representation } \\
\text { of spatial data infrastructure }\end{array}$ & {$[21]$} \\
\hline SimStadt & New Urban Simulation Environment & $\begin{array}{l}\text { virtual 3D city models and visualisation sup- } \\
\text { port }\end{array}$ & [22] \\
\hline
\end{tabular}

- Commodities: it represents any property (in MWh) that can be generated, consumed, transmitted and/or stored. In urbs, commodities can represent Demand like electricity time series, Supply (SupIm) such as time series of intermittent renewable energy resources, Stock representing any purchasable goods like biomass, or Environmental commodity which represents the amount of GHGs. Environmental commodities have a maximum allowed quantity that may be created as an option to investigate the effect of policies on the model outputs [27]. In this study, the Environmental commodity has no limit as this function is beyond the purpose of this paper.

- Processes: describes the conversion technologies which convert commodities to different forms of energy such as wind turbines and solar panels. The ratios of input and output of the conversion process constitute one of the main required technical parameters of the urbs tool. While process or technology costs are the economic input data.

- Storage: defines the option to store energy for defined charging/discharging efficiencies. Storage in urbs is characterised by capacities both for energy content (in MWh) and charge/discharge power (in MW). Both capacities have independent sets of investment, fixed and variable cost parameters allowing various choices of storage technologies.

- Transmission: provides the possibility of exchange and transportation of commodities between defined locations. Like the entity "processes", transmission is also defined by costs efficiency.

In urbs, two types of objective function are provided. The default options optimises the total system costs and a second options allows for minimising the total $\mathrm{CO}_{2}$ emissions. In this work, the first option (cost-minimisation) was used. As an interface to the different available optimisation solvers such as CPLEX, GLPK or Gurobi, urbs uses the open source package pyomo [28, 29]. urbs can be used with different linear programming solvers [26]. In this work, the authors used the GNU Linear Programming Kit (GLPK) package [30] (default option) for solving the optimisation problem.

The objective function (equation (1)) (See [27, 26]) includes investment, fixed, variable, imported energy, fuel and revenue costs for each commodity, as follows:

$$
\xi_{\text {total }, j}=\xi_{i n v, j}+\xi_{f i x, j}+\xi_{\text {var }, j}+\xi_{i m p, j}+\xi_{f u e, j}+\xi_{\text {rev }, j}
$$

where $\xi_{\text {total }, j}$ is the total system costs in energy cell $j, \xi_{i n v, j}$ is the investment costs representing installation costs of new power/storage technologies in energy cell $j$. The fixed costs $\xi_{f i x, j}$ are mainly the maintenance and operation costs and the variable costs variable $\xi_{\text {var }, j}$ are assigned for energy technologies with rotating or moving parts (such as wind turbines). In $u r b s$, electricity prices from energy exchanges between the modelled UES and external markets (such as the national grid) can be considered as time-dependent, i.e. prices vary over the simulated time span. In this contribution, the electricity prices are considered to be variable. The time series of the online electricity prices are calculated as a function of local demand and supply which has been proven to be a reliable estimation [27].

FlexiGIS provides highly resolved time series of electricity demand and supply for each existing urban object. The urbs model was used with the FlexiGIS datasets as input to solve the linear optimisation problem. However, urbs requires a lot of assumptions to calculate time series of electricity demand. This is considered as one of the main shortcomings of urbs [26]. For the estimation of spatial energy consumption urbs is coupled with the open source energy infrastructure model rivus [31]. However, using buildings as the smallest spatial urban unite is beyond the rivus resolution [26], therefore, the energy demands are assigned on street segments and edges. FlexiGIS covers these shortcomings by providing a validated model for simulating urban electricity consumption and generation down 


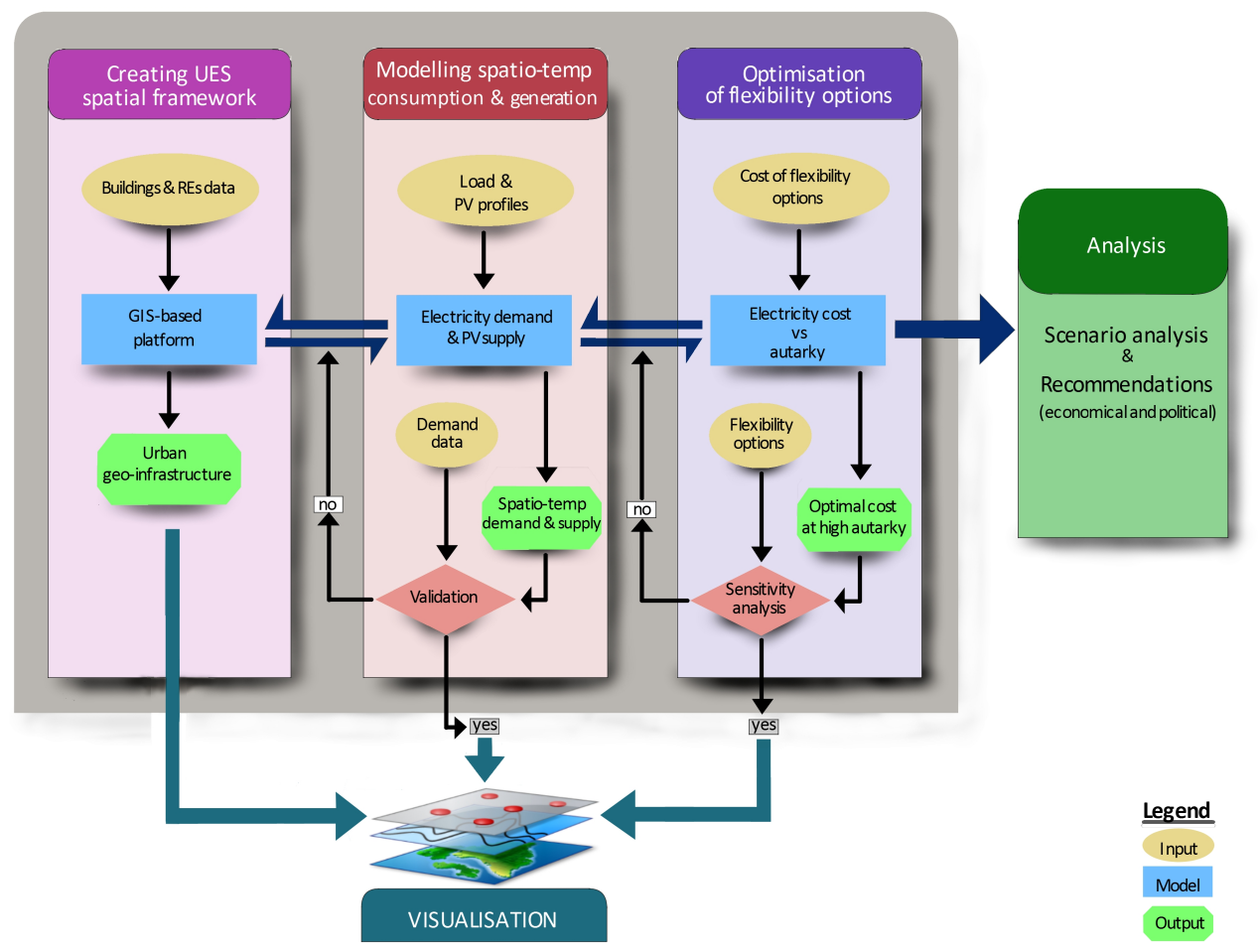

Figure 1: Outline of the FlexiGIS platform with its main working modules. The different data inputs, outputs and models involved in each module are shown [23].

to smallest urban object (such as buildings and streets).

\section{Data sources and collection}

Acquisition and collection of quality datasets is an essential but generally a challenging task energy system modelling and analysis at all scales. The following subsections briefly outlines the data collection techniques in FlexiGIS as well as the data sources used. These datasets, as stated above are then used as input for performing the optimisation in urbs.

\subsection{Urban infrastructure datasets}

Modelling urban energy systems requires an access to different sets of raw geo-referenced datasets at the urban level. Such datasets consists of, but is not limited to, building infrastructures and transport roads. Building data includes usage portfolios categorised in this study into agricultural, industrial, commercial, educational and residential. Moreover, street dataset portfolios include motorway, primary, residential, service, their geometrical parameters such as area values and roof-top shapes. In FlexiGIS, the required spatial datasets is automatically extracted from OpenStreetMap database (OSM) and processed accordingly ${ }^{1}$. The renewable capacities data were extracted from publicly available EnergyMap.info database [33, 23].

\footnotetext{
${ }^{1}$ A quality assessment of OSM datasets for modelling UES was already conducted by the authors for the case study of Oldenburg [32]
}

\subsection{Electricity generation and consumption datasets}

In FlexiGIS, the electricity demand is calculated for each exiting urban object with 15 minutes resolution at the finest spatial granularity (building, street, square) using the publicly available Standard Load Profiles (SLP). SLPs are developed by the German Ministry of Energy and Water BDEW ${ }^{2}$. MERRA and SoDa weather datasets for modelling local renewable power generation are used in FlexiGIS. The generated datasets of urban electricity demand and supply were validated against measured datasets provided by the grid operator EWE [24]. These datasets are the input time series for the urbs model for the optimisation simulations.

\subsection{Economic and technical parameters}

In addition to electricity demand and supply time series, the optimisation of storage in urbs requires technology specifications and details like the efficiencies of renewable and storage technologies. The required relevant technical parameters used here were extracted from the International Renewable Energy Agency (IRENA) [34] report. The type of installed power capacities, their capacities, average power production were extracted from EnergyMap.info.

Power and storage technology have a specific sets of price signals. The required economic parameters for the optimisation, such as the investment, fixed and variable costs were extracted from [35] for the relevant technologies (See Tables 3

\footnotetext{
${ }^{2}$ BDEW website
} 
and 4). The electricity prices are considered to be as a function of time and local electricity consumption and power generation from RES.

In $u r b s$, the only input parameter that is not defined by the user is the Annuity Factor $A F$. This parameter (equation 2) is used to calculate the present value of future fixed annuities [27]. $A F$ is derived for each power and storage technology from the two respective parameters $i$ and $n$ using the following equation:

$$
A F=\frac{(1+i)^{n} i}{(1+i)^{n}-1}
$$

where $i$ is the interest rate [\%] of costs for capitals after taxes, it is represented here by the weighted average cost of capital WACC. $n$ represents the respective number of depreciation periods in years (See Table 4).

\section{Case Study}

In this Section, FlexiGIS is applied and showcased for the city of Oldenburg because of the availability of the required validation datasets including district level real electricity demand and supply provided by the regional network operator EWE Netz. The optimal total system costs and operation of battery storage were investigated for the following scenarios: Reference scenario, Islanded scenario, RES-Mix and Future (2030) scenario. Table 2 elaborates the details and assumptions of each scenario.

The Reference scenario investigates the status quo of the energy system in Oldenburg where, the installed capacities (see Figure 3) remain fixed while being allowed to exchanges electricity with the national grid. In the Islanded scenario we assume that the investigated energy system is isolated (not connected to the national grid). This means that, the power generation, consumption and storage occur locally. Here, the power generation capacities are considered variable and the model optimises the required capacities to match the local demand.

In the Renewable Energy Sources Mix (RES-Mix) scenario, the energy system is connected to the national grid while the model optimises the power generation portfolio to meet the demand. The energy system can either purchase, feed-in the generated power to the national grid and/or store the excess energy in batteries. Finally, in the Future scenario we assume that the total costs of the emerging storage and micro-generation technologies will decrease by $61 \%$ and $58 \%$ by 2030 for Li-ion and PV; respectively [35]. This scenario investigates how this cost reduction in storage facilities will influence the planning and operation of storage and the resulting power mix.

New systematic approaches such as the cellular approach are considered as critical components to enable the optimal integration and operation of new technologies including storage technologies. The cellular approach is introduced ${ }^{3}$ [36]. It provides

${ }^{3}$ The cellular approach was proposed by the German Association for Elec- a conceptual framework for simulating energy systems on different scale, starting from the finest granularity (smallest unit energy cell) up to the national scale $[36,37]$. Within this context, energy cells [38] are basically established at the local scale and interconnected to each other at the same level. An energy cell can be a building, neighbourhood, district, or a city up to the regional and national scales [36].

The cellular approach allows for balancing local energy generation and consumption at the very lowest level and ought to be implemented in every single energy cell. This means, energy should be directly consumed and/or stored where it is produced (i.e. within the boundaries of the defined energy cell) without being fed into the national grid.

FlexiGIS simulations (See [24]) are performed and validated at the level of electrical power substations which are referred to as distribution transformers districts, e.g. Figure 2. Following the concept of the cellular approach (i.e. balancing the demand and supply at the smallest available urban granularity), the transformers districts are considered as the energy cell. To investigate this concept, two main cases are considered here:

- Case I: examines a centralised urban energy system considering the whole city a single (energy cell). In this case, the modelled electricity consumption is locally matched using the available urban renewable power generation within the defined geo-boundaries of the city of Oldenburg. The modelled system can exchange electricity with the national grid for a given electricity online price.

- Case II: the city of Oldenburg is divided into seven connected energy cells (or districts), each energy cell has a unique set of urban settlements leading to specific local electricity load and supply profiles. As shown in Figure 2, all districts are connected to each other by the existing transmission cables allowing an instantaneous exchange of electricity between the cells. This case considers a decentralised city and compares the total system costs and the feasibility of such urban energy systems.

FlexiGIS limits the installation of wind turbines in central districts allowing them only in suburban ones in order to account for local restrictions. The simulation of solar power generation considers the roof-top shapes and available areas following a roof-top assessment (performed in module I). The transformers districts ${ }^{4}$ define the geo-boarders of the investigated cells (see Figure 2). We assume that, the measured and generated electricity demand and supply occur inside the boundaries of each district. In Case I, the urban energy system is a single energy cell which can exchange the electricity only with the public grid. The power exchange in Case II occurs between the defined districts or energy cells as well as with the national grid.

\footnotetext{
trical, Electronic and Information Technologies (VDE) as a platform for investigating future scenarios for planning energy systems

${ }^{4}$ The validation datasets are provided at the level of electrical substations
} located in the transformers districts 
Table 2: Details and settings of the investigated scenarios

\begin{tabular}{|c|c|c|c|}
\hline \multicolumn{4}{|c|}{ List of scenarios } \\
\hline Scenario & Power capacities & Grid connection & Technologies costs \\
\hline Reference & current installed capacities & connected to the national grid & today's costs \\
\hline Islanded & variable & not connected & today's costs \\
\hline RES-Mix & variable & connected & today's costs \\
\hline Future $(2030)$ & variable & connected & future's costs \\
\hline
\end{tabular}

Figure 2 depicts the extracted urban geo-data and installed renewable capacities for the city of Oldenburg. The distribution of existing installed capacities is as follows: 63.8MW PV, 18.9MW wind, $12.3 \mathrm{MW}$ bio, $1.8 \mathrm{MW}$ gas and $700 \mathrm{~kW}$ hydro.

Lithium-ion (Li-ion) battery technology was selected as a storage technology in this study for two reasons. First, Li-ion battery systems currently dominate the market in Germany, particularly lithium iron phosphate (LFP) [35]. Second, this storage technology offers attractive characteristics for urban stationary applications in terms of thermal stability, safety, life cycle and costs $[39,40]$. The technical and economic costs of the renewable and storage technologies are shown in Table 3 provided by IRENA [35]. The full load hours (FLH) of wind and PV are 2350 and 850 hours, respectively and are calculated based on data provided by [33] for the city of Oldenburg.

We assume that, the maximum installed capacities of hydro, bio and gas will not change. The upper limit of storage capacity will be defined by the optimisation for each scenario. The energy efficiency of the storage process is 0.95 for both charging and discharging.

\section{Results and Discussion}

The scenarios investigated were applied for the two previously defined cases, (I and II). A linear optimisation problem is solved for one year with an hourly resolution (i.e. 8760 simulation time steps). The cost function is based on instantaneously matching the local electricity demand using available installed capacities while minimising the system costs. The following sections present the results for both investigated cases and for all scenarios.

\subsection{Case I: City-wise}

In Case I, the city is considered as an individual system that can interact with the power grid. Module III of the FlexiGIS model (i.e. the linear optimisation) is executed for all scenarios in Case I. An exemplary result for scenario RES-Mix on Figure 3(a) which illustrates hourly time series of energy balance for an arbitrary week obtained using urbs. The results represent the optimal configurations and operation of on-site microgeneration and power exchange to satisfy the local consumption (black curve) at the minimum system costs.
The comparison script "comp.py" provided by urbs is executed to create a cross-scenario analyses illustrating the results in tabular and graphical forms for all investigated scenarios in both cases (e.g. See Figure 3 and Table 5). Figure 3(b) depicts the cost-optimal operation of storage for the same week with an hourly resolution. Note that, in case of overproduction, the energy cell either feeds the surplus electricity into the power grid at a profit or stores it in batteries. However, electricity is bought at any price if the consumption is higher than local generation, as the energy demand must be covered simultaneously every hour.

Figure 4(a) and Table 5 illustrate the minimum system costs which resulted from the optimisation runs for three investigated scenarios (Reference, RES-Mix and Future) in both cases (I and II). Figure 4(b) depicts the optimal power generation mix from dispatchable renewable power generation and exchange from the power grid. The total costs are the sum of investment costs, fixed, variable costs, electricity purchase price and revenues (in case of feed-in). For the Reference scenario Case I, the electricity imported from the power grid accounts for more than $75 \%$ of the power generation mix. However, the total system costs decrease when the share of renewables increases. This is the case for the RES-Mix and Future scenarios, although more investments costs for renewables and storage capacities are required. As shown in Figure 4(a and b), the total costs in Case I are reduced by $28 \%$ and $45 \%$ for RES-Mix and Future scenarios; respectively when compared to the Reference scenario.

In the Islanded scenario, the minimum system costs for Case I increase dramatically (four times the total costs as in Reference) due to the lacking exchange with the power grid. This also resulted in the significant investments in storage and in increasing power capacities. For the Future scenario, the total system costs are reduced due to the reduction in the storage and power technologies costs. This is reflected in the decreasing share of the required electricity from the external power grid which is about $11 \%$ while the remaining $89 \%$ comes from local on-site renewables. In other words, the widespread of local renewable and storage technologies increase the energy selfsufficiency of cities by reducing the need of power exchange with the grid.

Additionally, the average price of the modelled electricity imported from the national grid accounts to 210 /MWh (See Figure 4 as well as in Table 5). Hence, it is worth mention- 


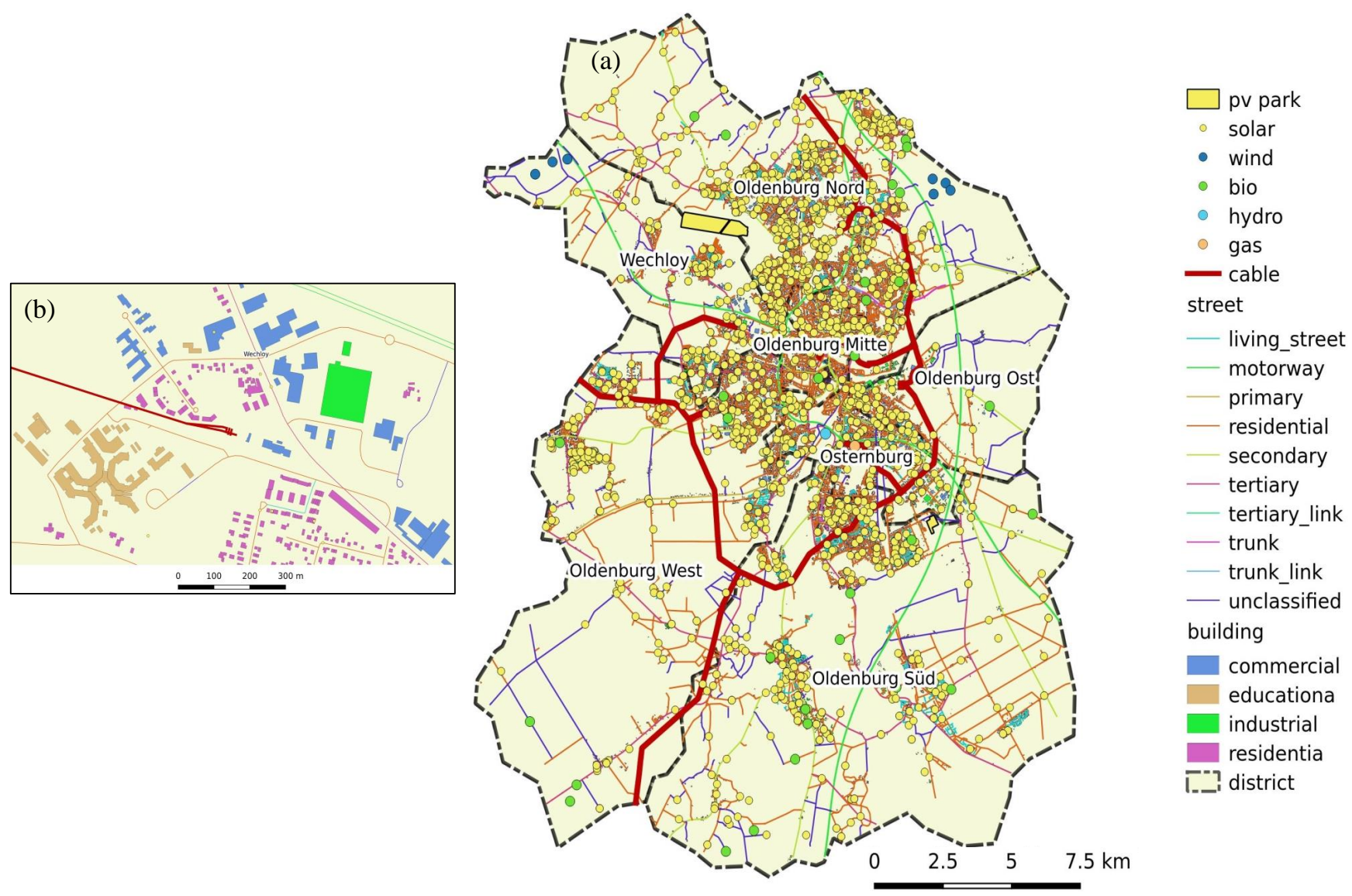

Figure 2: Cartographic representation of the urban energy infrastructure for the case study of Oldenburg, (b) zoomed view of the extracted and processed building clusters. Credits: EnergyMap.info, QGIS and OpenStreetMap contributors.

ing that the taxes are included in the costs of electricity which elaborates the costs reductions in both RES-Mix and Future scenario.

Table 6 depict the results obtained by urbs for the four investigated scenarios. It shows that, the concept of ('isolated city) is not economically beneficial. When aiming towards achieving technical feasibility, the costs are still too high to operate the system as an island. Therefore, the island concept is neither advantageous nor economically profitable for the investigated case study of Oldenburg. For the Future scenario, if the price decrease following the predicted trend, the possibility of integrating storage and renewables is higher. Overall, it is clear that, the total system costs will be reduced for a higher penetration of flexibilisation and renewable energy technologies.

\subsection{Case II: District-wise}

This case considers a decentralised energy system where the city is divided into subsystems connected by the existing transmission network (see Figure 2). FlexiGIS is again used to de- rive the geo-urban infrastructure and the demand and supply in each district. In a next step, the optimisation is performed considering the connected districts. Figure 5 illustrates the optimised total system costs and power generation mix for the investigated scenarios. As shown in Table 6, although the renewables, storage and transmission capacities are set as infinite, the optimisation for the Islanded scenario in Case II has no feasible solution. These result confirm the fact that an isolated energy cell (autonomous city) is technically and economically not realistic in terms of required installed capacities and system costs.

As depicted in Figure 5 for the Reference scenario, the share of the imported energy from the external power grid (represented by the purchasing item) prevails in the power generation mix (accounting for about two thirds of the required energy]. Similarly to Case I, the optimisation resulted in the storage option not being chosen in this scenario. This is economically unattractive due to less shares from renewables and cheaper electricity from the power grid. In addition, as wind power 
Table 3: Economic parameters of the investigated power and storage technologies as input for urbs.

\begin{tabular}{|l|l|l|l|l|l|l|}
\hline & \multicolumn{5}{|c|}{ Renewable technologies and storage costs [€] } \\
\hline & $\mathbf{P V}[€ / \mathbf{k W}]$ & Wind $[€ / \mathbf{k W}]$ & Hydro[€/kW] & Gas [€/kW] & Bio [€/kW] & Li-ion [€/kWh] \\
\hline Invest. costs & 932 & 1539 & 1701 & 900 & 1215 & 405 \\
\hline Fixed costs & 9.3 & 53 & 68 & 10 & 39 & 4 \\
\hline Var. costs & 0 & 0.02 & 0.06 & 0.05 & 0.04 & 0 \\
\hline
\end{tabular}

Table 4: Technological specifications of the investigated power and storage technologies as input for urbs.

\begin{tabular}{|l|l|l|l|l|l|l|}
\hline & \multicolumn{5}{|c|}{ Technical parameters of RE and storage technologies } \\
\hline & PV & Wind & Hydro & Gas & Bio & Li-ion \\
\hline Depreciation [year] & 25 & 25 & 50 & 30 & 25 & 15 \\
\hline WACC & 0.07 & 0.07 & 0.07 & 0.07 & 0.07 & 0.07 \\
\hline Installed cap. [MW] & $63.8 \quad 18.9$ & 0.7 & 1.77 & 12.3 & 0 \\
\hline Maximum cap. [MW] & $\begin{array}{l}\text { st. available } \\
\text { rooftop areas }\end{array}$ & $\begin{array}{l}\text { st. available areas } \\
\text { in only suburban }\end{array}$ & 0.7 & 1.77 & 12.3 & not limited \\
\hline
\end{tabular}

generation have an upper limit (they are only allowed in suburban areas), the optimised wind power generation approaches its maximum allowed value of almost 550GWh for both RESMix and Future scenarios (See Figure 5). On the other hand, the cost reduction and available rooftop areas in this case study allow for more PV installations in the future scenario.

For all scenarios, the system tends to invest more in storage, renewables and transmission capacities in Case II. For example, the total required battery storage capacity in scenario RESMix amounts to $71 \mathrm{MWh}$ in Case I compared to $173 \mathrm{MWh}$ in Case II. Therefore, the total system costs are between 10\%$13 \%$ higher than in Case I for RES-Mix and Future scenarios. However, the share of the imported power from the grid is less in Case II. In this regard, the investigated energy system in Oldenburg inclines to be more energy self-sufficient when the districts are considered (Case II) rather than considering the system as a single energy cell as in (Case I).

Moreover, unlike Case I, districts in Case II are connected to each other by the available transmission cables which allow energy exchange between energy cells. Thus, facilitating local energy consumption and generation within the city boundaries. Therefore, the energy cells in Case II have higher selfsufficiency than in Case I. In Figure 6(b), the size of the pie chart represents the simulated demand in each district and the optimal mix to locally meet this demand. As illustrated, the wind turbines are installed only in the outer districts. Obviously, more local insights can be revealed in Case II. This is due to a more detailed representation of the urban infrastructure as well as the power exchange between districts. We conclude that, each energy cell tends to be more self-sufficient by locally generating, storing and consuming energy. Comparing the costs with a more centralised system (Case I Figure 6(a)), we found that, the total system costs decreased by $10 \%$ because $9.3 \%$ more storage was installed for a single energy cell. However, the imported energy increases by more than $18 \%$, which means a more pronounced dependency and pressure on the power grid.

However, it was assumed that, the imported energy comes from fossil-based power generation plants. It will be interesting to investigate the effects of importing energy which is produced by renewable energy plants.

Furthermore, it seems that smoothing the load curve through aggregation (See Figure 7) results in lower levels of selfsufficiency. As an example, Figure 7 illustrates the aggregation effect of different urban load profiles. It shows the simulated electricity consumption for a typical day in 2015, that are normalised to its mean values, for exemplary urban granularities: Households in Osternburg district, aggregated street lights (for all roads in the same quartier), Osternburg district and the city scales. Through aggregation, the city scale load profile became smoother. Nevertheless, which urban energy system (centralised or decentralised) is more sustainable is still an open question and requires further investigations.

Next section introduces a new development of FlexiGIS. It performs a potential assessment of the required spaces in urban energy infrastructure to find the best placement for battery storage.

\section{Localisation of decentralised storage}

An ongoing development of FlexiGIS is the potential assessment and localisation of the required area for stationary storage applications by deploying GIS techniques. A review study [41] revealed that, none of the reviewed models and tools provided the option of finding the best place of the distributed battery systems in the urban context using GIS. This work contributes to fill in this gap by introducing a concept of GIS-based heuristic approach for the allocation of battery storage in cities.

In some previous contributions, different approaches were used to find the best siting of various storage technologies. For instance, [42] developed semi-definite relaxation approach to optimally locate large-scale energy storage in power grids with wind and conventional power generations. While [43] introduced a model for storage sizing and location using a linearised 


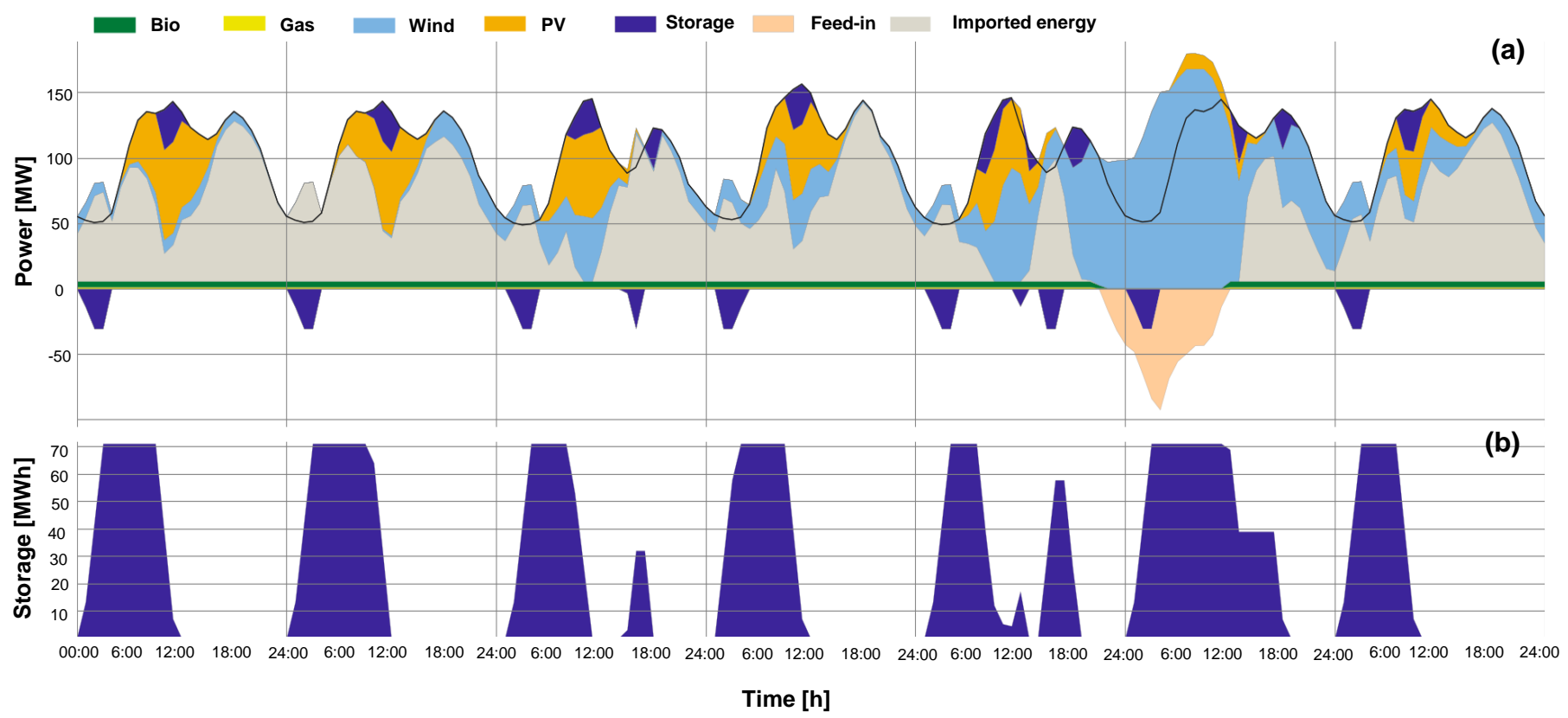

Figure 3: For the RES-Mix scenario in Case I: (a) hourly time series of electricity demand (black curve) and supply from available sources and (b) the optimal storage capacity and operation at the minimum system costs resulted from urbs over an arbitrary week for Oldenburg.

Table 5: The optimal system costs for the investigated scenarios in Case I for the city of Oldenburg using urbs.

\begin{tabular}{|l|l|l|l|l|l|l|l|}
\hline & \multicolumn{7}{|c|}{ System costs $\left[10^{6} €\right]$} \\
\hline Scenarios & Investment & Fixed & Variable & Imported Energy & Fuel & Revenue & Total costs \\
\hline Reference & 0 & 2.15 & 2.88 & 176.82 & 1.03 & 0 & 182.89 \\
\hline Islanded & 574.83 & 68.82 & 76.46 & 0 & 0.16 & 0 & 720.27 \\
\hline RES-Mix & 36.31 & 11.5 & 16.26 & 68.03 & 0.7 & -1.26 & 131.55 \\
\hline Future & 46.27 & 10.21 & 12.49 & 30.27 & 0.62 & -1.78 & 98.07 \\
\hline
\end{tabular}

multiperiod optimal power flow method. On the other hand, the authors in [44] proposed a method for the integration of sizing, placement and operational strategies of batteries into an Optimal Power Flow (OPF) distribution grid planning tool. In [45] a GIS-based model for the placement of pumped hydro energy storage was introduced. However, reviewing the literature reveals that,the developed methods using GIS techniques for localisation and optimisation of stationary storage battery systems are still at an early stage [23].

Principally, the stationary storage battery systems can be installed at various levels within the electricity supply network such as within the transmission grid, on the distribution network or down to the individual building units. As an example, for a neighbourhood in Germany with 10 residential buildings and high PV penetration, [46] compared community scale storage solutions to distributed storage systems in each single building. The authors concluded that, the centralised community storage exhibits various benefits: First, the total required storage capacity is reduced significantly at equal self-sufficiency degrees. In addition, the total system costs are decreased compared to the distributed building storage systems. More importantly, [46] highlighted that in modern houses and buildings it is not always possible or convenient to accommodate on-site storage systems.
Therefore, the localisation of community battery storage is highly dependent on the distribution grid structure and should take the following criteria into consideration:

- The battery storage should be located to allow for less renewable power curtailments. In other words, it should be close to position of on-site renewable power microgeneration

- The community battery storage should be located on the grid in order to save and reduce network losses and in due course to increase the profit of energy arbitrage on the market

- Particularly in residential areas, the battery storage stations should be incorporated only into secure and save areas

- The availability of the required spaces in the urban infrastructure is crucial and should be taken into account

It is worth mentioning that unlike high voltage transmission grid, the major part of low voltage distribution system, in general, is underground. Therefore, it is a hard task to map the distribution network, particularly distribution cables, on OpenStreetMap. However, few parts of the distribution grid like 


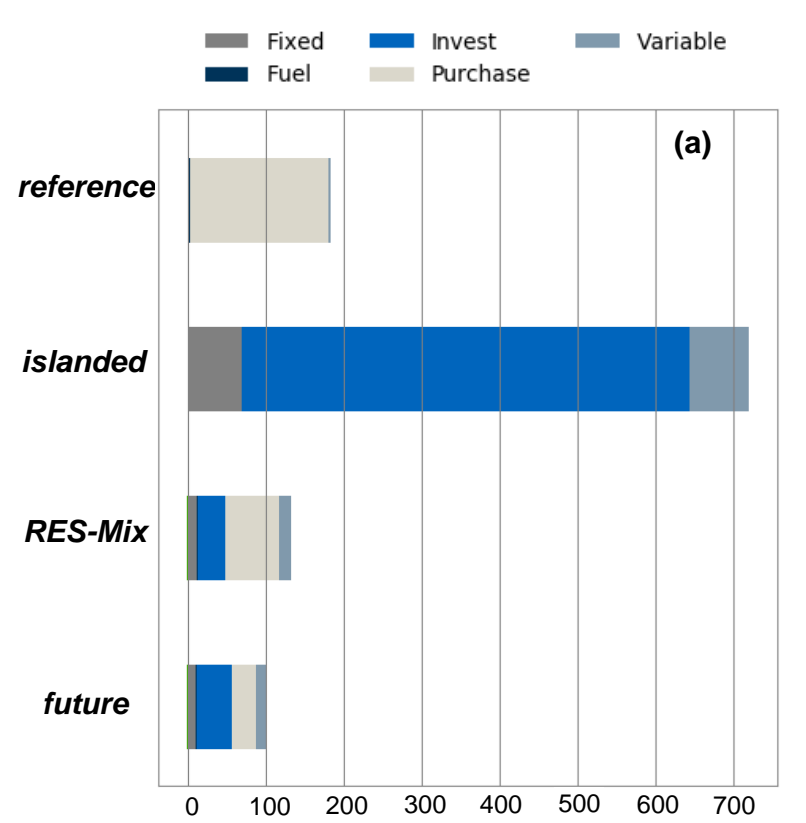

Total costs $\left(10^{6}\right.$ Euro/year)

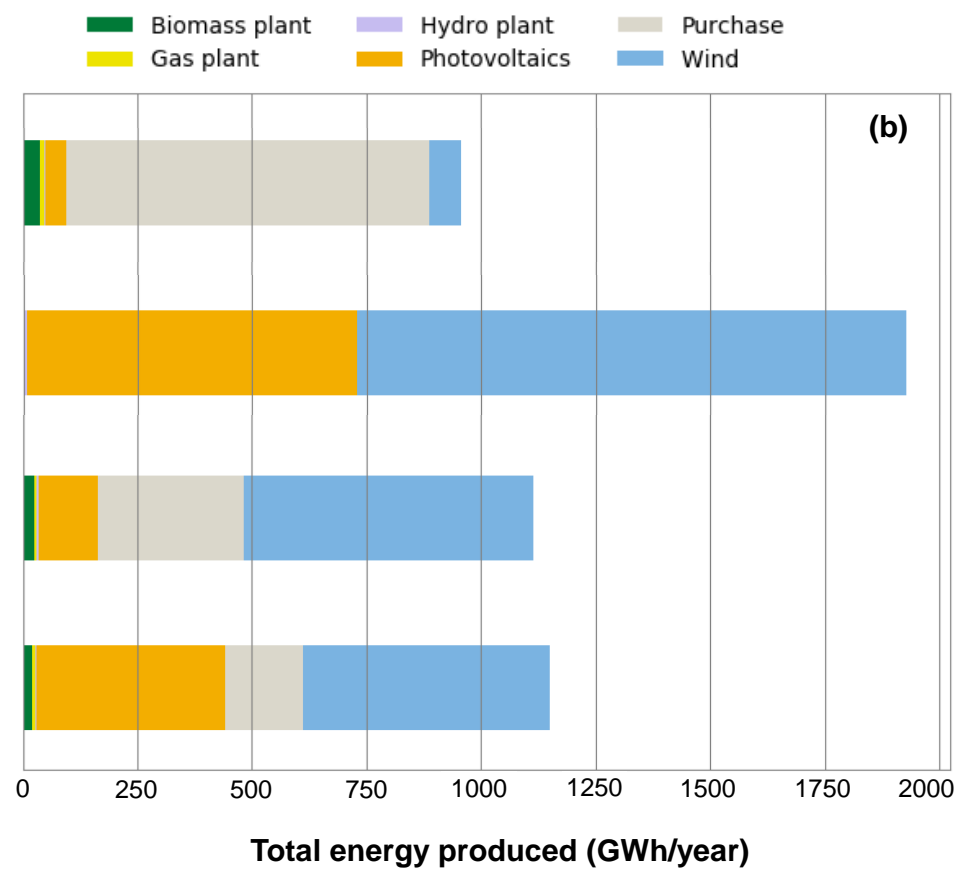

Total energy produced (GWh/year)

Figure 4: A comparison between the investigated scenarios in Case I for (a) The optimal total costs of urban electricity systems per year, and (b) its respective optimal power generation mix using urbs.
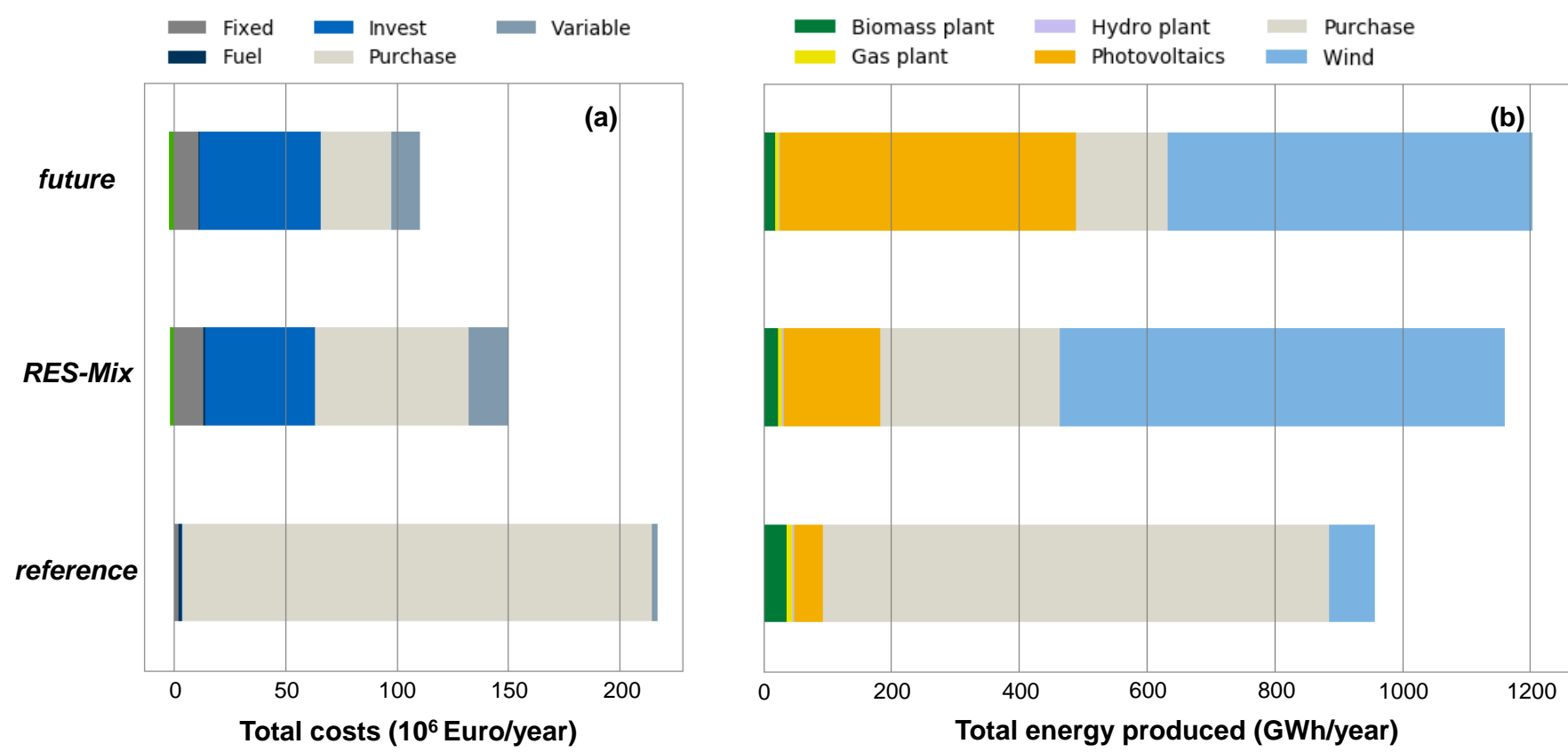

Figure 5: (a) The total annual costs of urban electricity systems in Case II for the different scenarios investigated, and (b) its respective power generation mix using urbs. Note, for the Islanded scenario in Case II the optimisation problem has no feasible solution. 
Table 6: The optimal system costs for the investigated scenarios in Case II for the city of Oldenburg using urbs.

\begin{tabular}{|l|l|l|l|l|l|l|l|}
\hline & \multicolumn{7}{|c|}{ System costs $\left[10^{6} €\right]$} \\
\hline Scenarios & Investment & Fixed & Variable & Imported Energy & Fuel & Revenue & Total costs \\
\hline Reference & 0.42 & 2.15 & 2.55 & 211.06 & 1.00 & -0.01 & 217.18 \\
\hline Islanded & \multicolumn{7}{|c|}{ No feasible solution } \\
\hline RES-Mix & 49.31 & 13.19 & 17.87 & 69.08 & 0.66 & -1.89 & 148.22 \\
\hline Future & 54.55 & 10.95 & 12.96 & 31.42 & 0.56 & -2.46 & 107.97 \\
\hline
\end{tabular}
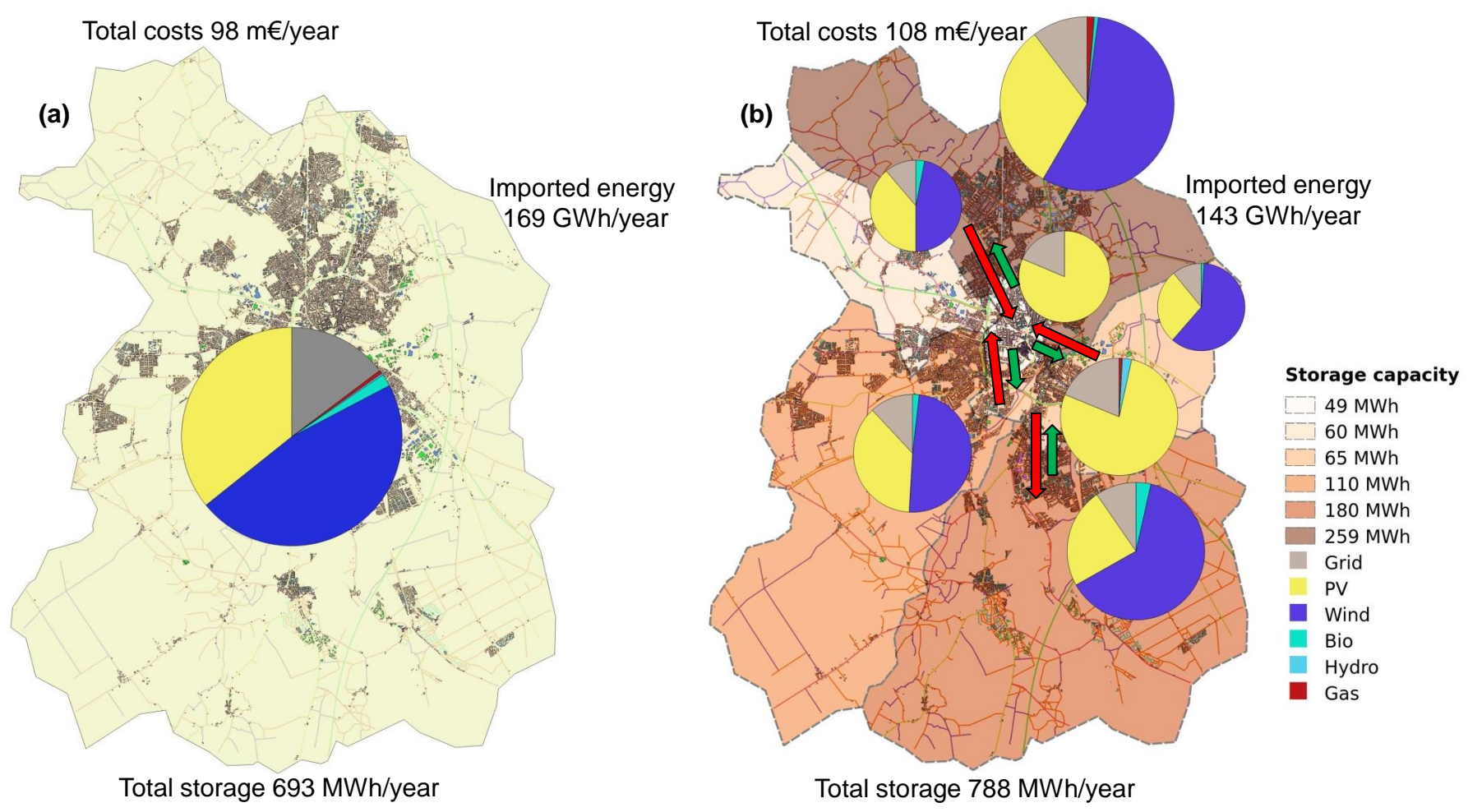

Figure 6: The optimal system costs and configurations of the power supply systems obtained by urbs for the Future scenarios for the city of Oldenburg in both cases. (a) single energy cell Case I and (b) Case II power generation mix and the required energy storage in each district.

transformers and substations (See Figure 2 can be easily accessible for OpenStreetMap mappers. Such components are in most cases located on secure plots and/or incorporated into buildings. The battery storage could be integrated into the distribution grid at or near load centres or close to the distribution transformers.

In this contribution, the authors introduce a simplified GISbased heuristic approach to find suited perspective sites of community battery storage. Taking the criteria cited above into account, the optimal battery storage placement is modelled as a function of storage capacity, local electricity demand and supply, the space availability and total system costs.

Figure 8 depicts the workflow of the approach used here to locate the distributed storage. The first step results in the creation of the underlying urban energy infrastructure. It includes processing, filtering and classification of the extracted raw urban datasets based on the urban portfolios. The resulted datasets are geo-referenced landuse, streets and buildings units (categorised into residential, commercial, educational, indus- trial and agricultural). In addition, the locations of electric substations and some of the distribution transformers are identified in this stage.

In a second step, the spatial and temporal distribution of electricity demand and supply down to the building and street level are simulated and validated against real data provided at the electric substations in the transformer districts (adopted here as energy cells). Then, spatial sub-clusters of consumers or buildings are heuristically defined based on the buildings density and the maximum residual load ${ }^{5}$.

The simulated residual load must be simultaneously met by energy from the battery storage. The optimised size of battery storage is performed in a third step using urbs at the defined energy cells. The total optimised storage capacity in each district is allocated and distributed to each sub-cluster determined in the previous step. The developed modelling strategy incorporates

\footnotetext{
${ }^{5}$ The residual load is the difference between local electricity consumption and on-site renewable power micro-generation
} 


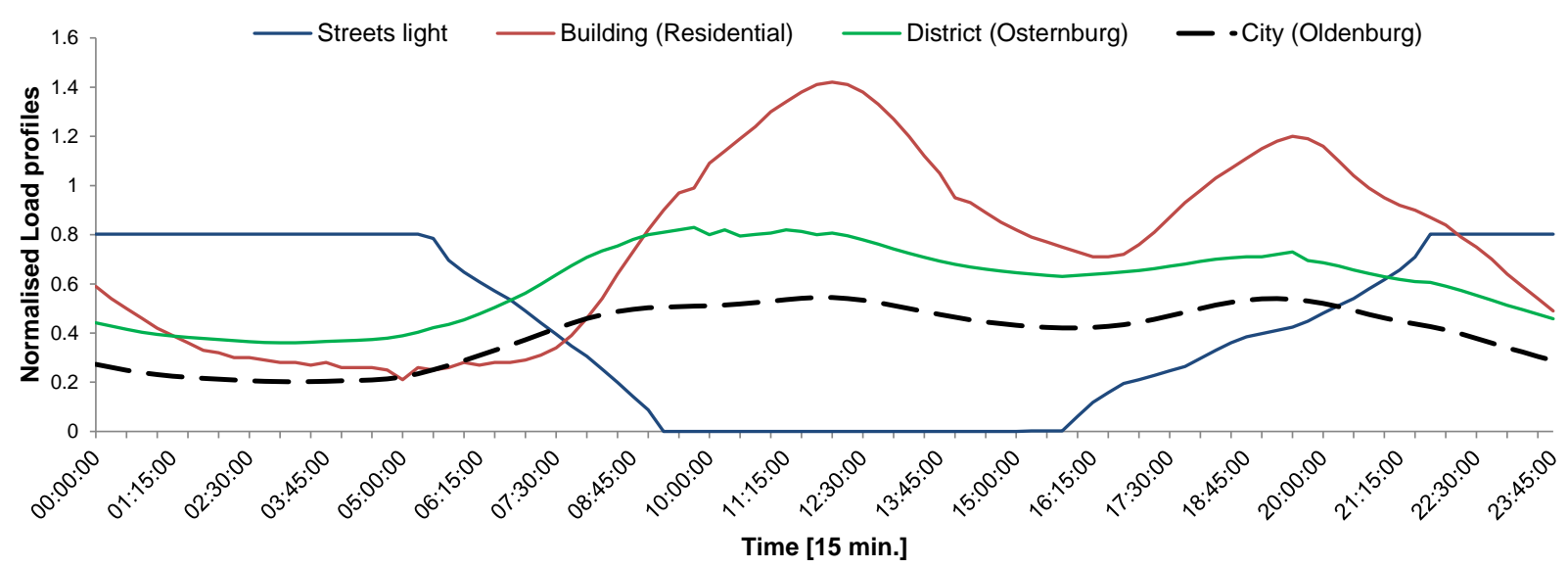

Figure 7: Quarter hourly time series of exemplary load profiles for a typical day in 2015 simulated using FlexiGIS (Module II)

both spatial and temporal dimensions by coupling electricity demand and micro-generation with the community battery storage. Through all the aforementioned steps, GIS is used. A key contribution of this research is the combination of GIS systems and open source data and tools.

Applying the proposed algorithm presented in Figure 8, Figure 9 (as an example) shows the prospective sites of the optimised decentralised battery storage in the district of Wechloy in the city of Oldenburg for the Future scenario in Case II. It illustrates the perspective locations of the community battery storage for each sub-cluster.

The potential assessment and localisation of the required area for the stationary storage capacities using GIS techniques on districts level provide a more realistic depiction of the resulting optimisation costs. The future deployment costs of reasonably sized and well located battery storage in cities can increase the rates of self-consumption. On-site battery storage thus has a major potential to reduce the total system costs, expand the utilisation of urban renewable energy and mitigate global warming effects.

\section{Conclusion and outlook}

Micro-generation in cities results in higher shares of fluctuating power supply which puts a significant pressure on the urban power supply system. However, electricity storage can play a central role in smoothing fluctuations caused by renewable energy generation. In this context, urban energy modelling can contribute effectively to planning the transition towards cleaner and affordable urban energy system.

This contribution introduced the open source platform FlexiGIS which generates datasets of the urban energy infrastructure, simulates consumption and generation and optimises local energy systems. FlexiGIS provides answers and insights into the planning of sustainable future urban energy systems. FlexiGIS was softly coupled to the open source optimisation model urbs. The goal is the optimisation of storage in urban energy systems. The optimisation was performed to investigate how the local demand can be met at minimum system costs using electricity storage and local renewable generation. Furthermore, a heuristic GIS-based method was developed to investigate the required area and best siting of future battery storage in cities.

By using the concept of energy cell it was shown that, the high level of details and granularity when modelling energy systems provides a more accurate and detailed input datasets for the optimisation model. Thus, resulting in more detailed and precise optimisation results. The energy cell concept lends support to a self-sufficient urban energy system while total system costs increased.

In the investigated case studies and scenarios, the authors found that a $100 \%$ self-sufficient city is economically not affordable and technically infeasible. On the other hand, the cost reduction potential of storage and new technologies can enhance high degrees of self-consumption by reducing total system costs. This represents a particularly attractive combination especially when the share of urban micro-generation is around $90 \%$. For a high share of RES, the total costs are reduced sharply by about $50 \%$ compared to the Reference scenario. Moreover, the optimisation results highlight that, stationary electricity storage can become increasingly competitive. Therefore, storage provides UES with a wide range of affordable energy services.

The presented heuristic approach is applied here only to locate the perspective sites for battery storage application and currently in further development. Nevertheless, this method will be further developed as FlexiGIS provides the framework for future investigations on other storage technologies and flexibilisation portfolios like electrical vehicles and heat pumps. Two main ongoing developments of FlexiGIS are currently under way. The first is an automation of of all modelling processes including data processing, extraction and export to a centralised 


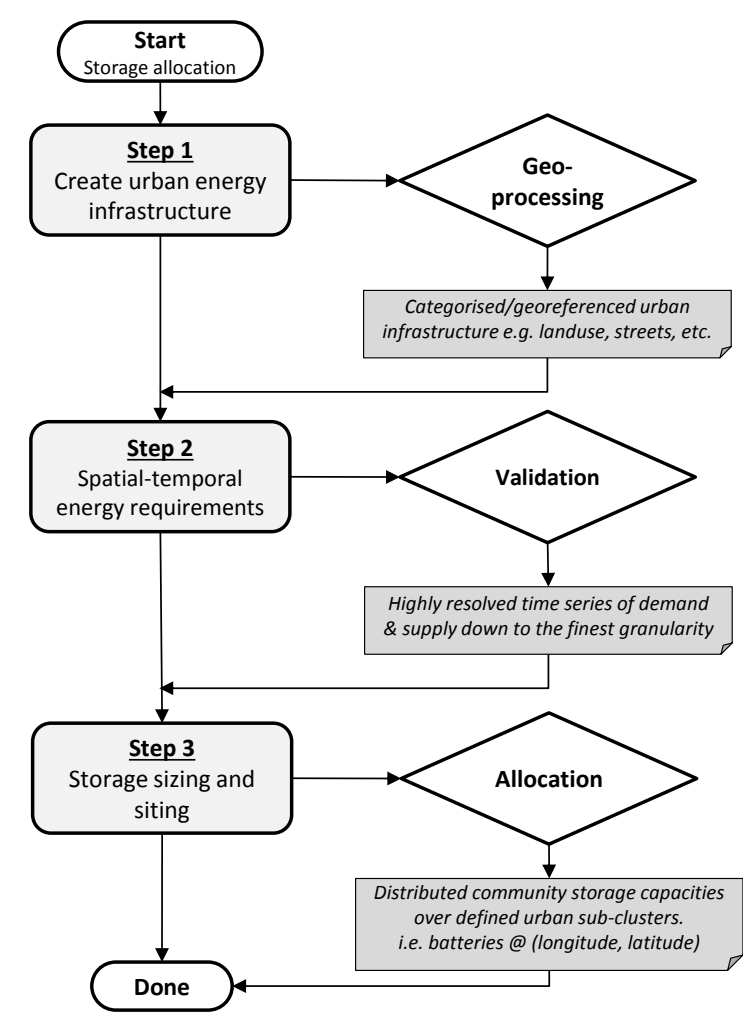

Figure 8: Workflow of the allocation of prospective sites for decentralised battery storage.

SQL database. Second, FlexiGIS uses solely publicly available datasets and tools. In this context, the documentation of all data acquisition and modelling processes is under development and the code is planned to be uploaded to GitHub.

\section{Acknowledgements}

The first author acknowledges the financial support provided by the Heinrich Boell Foundation through a PhD scholarship. The authors would like to thank the EWE-Netz for providing the required validation data.

\section{References}

[1] Alhamwi A, Medjroubi W, Vogt T, Agert C. FlexiGIS: an open source GIS-based platform for the optimization of flexibility options in urban energy systems. Energy Procedia. 2018;152C:944-949. Available from: https://doi.org/10.1016/j.egypro.2018.09.097.

[2] Johansson TB, Patwardhan AP, Nakićenović N, Gomez-Echeverri L, et al. Global Energy Assessment - Toward a Sustainable Future. Cambridge University Press and IIASA; 2012.

[3] James Keirstead Nilay Shah. Urban Energy Systems. Routledge; 2013. Available from: https://doi.org/10.4324/9780203066782.

[4] IEA. World Energy Outlook 2017. OECD; 2017. Available from: https : //doi.org/10.1787/weo-2017-en.

[5] Hawley AH. World Urbanization: Trends and Prospects. In: Population Growth. Routledge; 2017. p. 70-83. Available from: https://doi . org/10.4324/9781315127002-6.

[6] UN. 2018 Revision of World Urbanization Prospects. In: World Urbanization Prospects. United Nations; 2018. p. -. Available from: https: //population.un.org/wup/Publications/.
[7] Mller DB, Liu G, Løvik AN, Modaresi R, Pauliuk S, Steinhoff FS, et al. Carbon Emissions of Infrastructure Development. Environmental Science \& Technology. 2013 oct;47(20):11739-11746. Available from: https : //doi.org/10.1021/es402618m.

[8] UN H. New Urban Agenda. The United Nations Conference on Housing and Sustainable Urban Development; 2016.

[9] Blau J. The Paris Agreement. Springer International Publishing; 2017. Available from: https://doi .org/10.1007/978-3-319-53541-8.

[10] Kraas F, Leggewie C, Lemke P, Matthies E, Messner D, Nakicenovic N, et al. Humanity on the move: Unlocking the transformative power of cities. German Advisory Council on Global Change; 2016.

[11] Kordas O, Liu G, Ulgiati S. Energy and urban systems. Applied Energy. 2017;Available from: https://doi.org/10.1016/j . apenergy . 2016.10.112.

[12] Robinson D, Haldi F, Kämpf J, Leroux P, Perez D, Rasheed A, et al. CitySim: Comprehensive micro-simulation of resource flows for sustainable urban planning. In: Proc. Building Simulation; 2009. p. 1614-1627.

[13] Nutkiewicz A, Yang Z, Jain RK. Data-driven Urban Energy Simulation (DUE-S): A framework for integrating engineering simulation and machine learning methods in a multi-scale urban energy modeling workflow. Applied Energy. 2018 sep;225:1176-1189. Available from: https : //doi.org/10.1016/j. apenergy.2018.05.023.

[14] Roche S. Geographic Information Science I, Why does a smart city need to be spatially enabled? Progress in Human Geography. 2014 feb;38(5):703-711. Available from: https://doi.org/10.1177/ 0309132513517365.

[15] Girardin L, Marechal F, Dubuis M, Calame-Darbellay N, Favrat D. EnerGis: A geographical information based system for the evaluation of integrated energy conversion systems in urban areas. Energy. 2010 feb;35(2):830-840. Available from: https://doi.org/10.1016/j. energy.2009.08.018.

[16] Schafers H, Kulus D. Analysis and location of demand side integration potentials in urban space using gis based digital city maps. In: 22nd International Conference and Exhibition on Electricity Distribution (CIRED 2013). Institution of Engineering and Technology; 2013. p. 1-4. Available from: https://doi.org/10.1049/cp.2013.1238. 


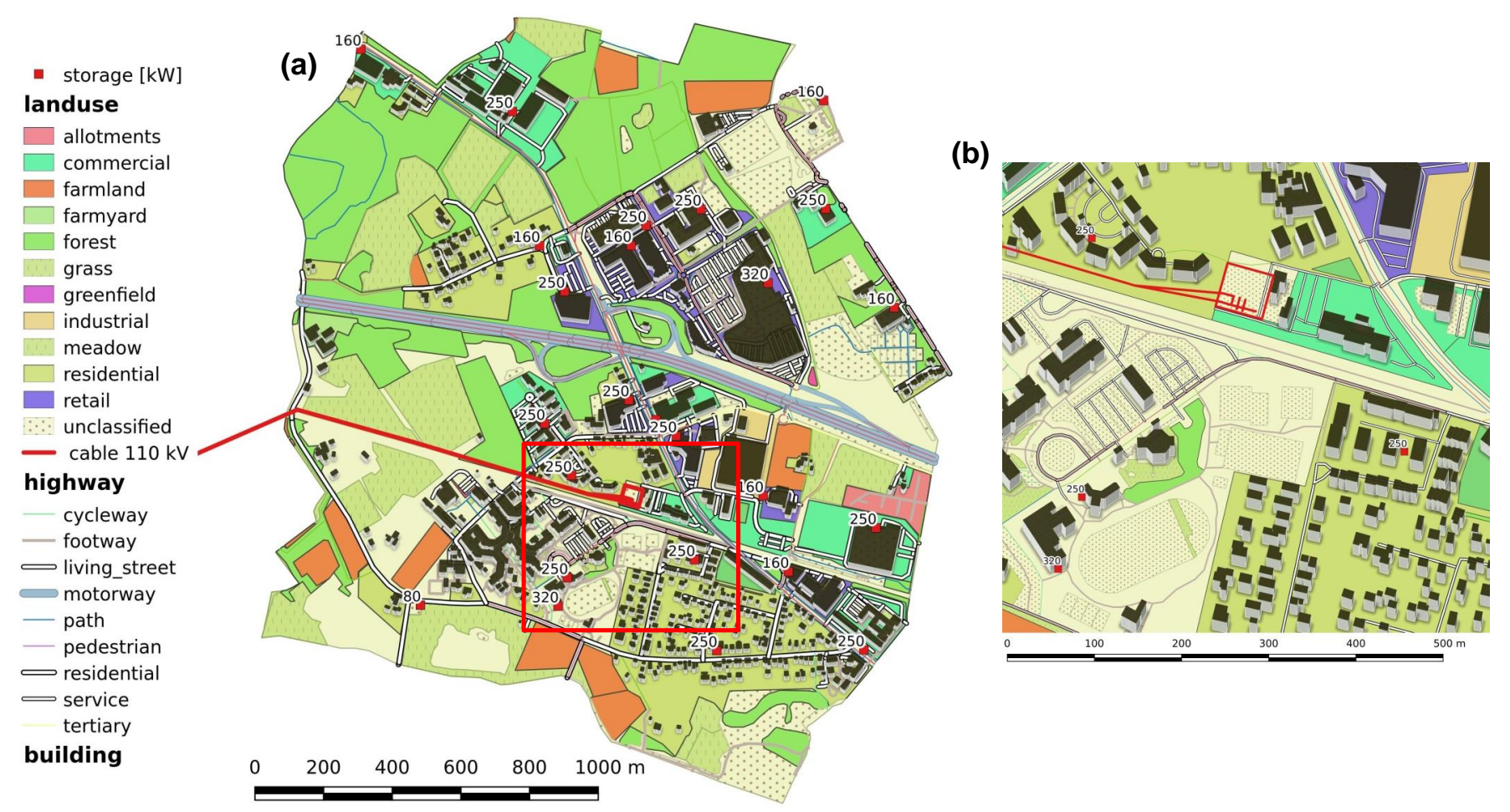

Figure 9: Allocation of prospective sites for decentralised battery storage in (a) Wechloy district in the city of Oldenburg and (b) zoomed area that shows the urban fabric and the distribution of the battery storage.

[17] Gennaro MD, Paffumi E, Scholz H, Martini G. GIS-driven analysis of emobility in urban areas: An evaluation of the impact on the electric energy grid. Applied Energy. 2014 jul;124:94-116. Available from: https: //doi.org/10.1016/j.apenergy.2014.03.003.

[18] Keirstead J, Samsatli N, Shah N, et al. SynCity: an integrated tool kit for urban energy systems modelling. Energy efficient cities: Assessment tools and benchmarking practices. 2010;p. 21-42.

[19] Robinson D, Campbell N, Gaiser W, Kabel K, Le-Mouel A, Morel N, et al. SUNtool - A new modelling paradigm for simulating and optimising urban sustainability. Solar Energy. 2007 sep;81(9):1196-1211. Available from: https://doi.org/10.1016/j.solener.2007.06.002.

[20] BOLLINGER LA, Evins R. HUES: A Holistic Urban Energy Simulation platform for effective model integration. In: Proceedings of International Conference CISBAT 2015 Future Buildings and Districts Sustainability from Nano to Urban Scale. EPFL-CONF-213425. LESO-PB, EPFL; 2015. p. 841-846.

[21] Kolbe TH, Grger G, Plmer L. CityGML: Interoperable Access to 3D City Models. In: Geo-information for Disaster Management. Springer Berlin Heidelberg; 2005. p. 883-899. Available from: https ://doi.org/10. 1007/3-540-27468-5_63.

[22] Nouvel R, BRASSEL KH, BRUSE M, DUMINIL E, COORS V, EICKER U, et al. SimStadt, a new workflow-driven urban energy simulation platform for CityGML city models. In: Proceedings of International Conference CISBAT 2015 Future Buildings and Districts Sustainability from Nano to Urban Scale. EPFL-CONF-213437. LESO-PB, EPFL; 2015. p. 889-894.

[23] Alhamwi A, Medjroubi W, Vogt T, Agert C. GIS-based urban energy systems models and tools: Introducing a model for the optimisation of flexibilisation technologies in urban areas. Applied Energy. 2017 apr;191:19. Available from: https://doi.org/10.1016/j. apenergy. 2017. 01.048.

[24] Alhamwi A, Medjroubi W, Vogt T, Agert C. Modelling urban energy requirements using open source data and models. Applied Energy. 2018 dec;231C:1100-1108. Available from: https://doi.org/10.1016/ j.apenergy.2018.09.164.
[25] Moyroud N, Portet F. Introduction to QGIS. In: QGIS and Generic Tools. John Wiley \& Sons, Inc.; 2018. p. 1-17. Available from: https: //doi.org/10.1002/9781119457091.ch1.

[26] Dorfner J. Open Source Modelling and Optimisation of Energy Infrastructure at Urban Scale. Technical University of Munich. 2016; doctoral thesis. Available from: https://dx.doi.org/10.5281/zenodo. 46118.

[27] Dorfner J. rivus: A mixed integer linear optimisation model for energy infrastructure networks. Technical University of Munich. 2018;Available from: https://media.readthedocs.org/pdf/urbs/latest/ urbs.pdf.

[28] Hart WE, Laird CD, Watson JP, Woodruff DL, Hackebeil GA, Nicholson BL, et al. Pyomo-optimization modeling in python. vol. 67. 2nd ed. Springer Science \& Business Media; 2017.

[29] Hart WE, Watson JP, Woodruff DL. Pyomo: modeling and solving mathematical programs in Python. Mathematical Programming Computation. 2011;3(3):219-260.

[30] Oki E. GLPK (GNU Linear Programming Kit). In: Linear Programming and Algorithms for Communication Networks. CRC Press; 2012. p. 2529. Available from: https://doi.org/10.1201/b12733-4.

[31] Dorfner J. Open Source Modelling and Optimisation of Energy Infrastructure at Urban Scale. Technical University of Munich. 2017;Available from: https://media.readthedocs.org/pdf/ rivus/latest/rivus.pdf.

[32] Alhamwi A, Medjroubi W, Vogt T, Agert C. OpenStreetMap data in modelling the urban energy infrastructure: a first assessment and analysis. In: Proceedings of the 9th International Conference on Applied Energy. vol. 142. Elsevier; 2017. p. 19681976. Available from: https: //doi.org/10.1016/j.egypro.2017.12.397.

[33] fr Sonnenenergie (DGS) e V DG. DGS, editor. EnergyMap.info. Database for renewable energy power plants in Germany. Deutsche Gesellschaft fr Sonnenenergie (DGS) e.V.; 2019. Available from: http://energymap. info/.

[34] Agency IRE. Renewable Power Generation Costs in 2017. IRENA; 2018.

[35] Agency IRE. Electricity Storage and Renewables: Costs and Markets to 
2030. IRENA; 2017.

[36] Benz T, Dickert J, Erbert M, Erdmann N, Johae C, Katzenbach B, et al. Der Zellulare Ansatz Grundlage einer erfolgreichen, regionenuebergreifenden Energiewende. VDE VERBAND DER ELEKTROTECHNIK ELEKTRONIK INFORMATIONSTECHNIK e.V.; 2015.

[37] Kriechbaum L, Bckl B, Vopava J, Kienberger T. SmartExergy - Primary Energy Efficient and Hybrid Grid Solutions for Municipal Energy Supply Systems. In: NEIS Conference 2016. Springer Fachmedien Wiesbaden; 2017. p. 133-139. Available from: https://doi.org/10. 1007/978-3-658-15029-7_21.

[38] Amado M, Poggi F, Amado AR, Breu S. A Cellular Approach to NetZero Energy Cities. Energies. 2017 nov;10(11):1826. Available from: https://doi.org/10.3390\%2Fen10111826.

[39] Omar N, Monem MA, Firouz Y, Salminen J, Smekens J, Hegazy O, et al. Lithium iron phosphate based battery - Assessment of the aging parameters and development of cycle life model. Applied Energy. 2014 jan;113:1575-1585. Available from: https://doi.org/10.1016/j . apenergy . 2013.09.003.

[40] Zaghib K, Dontigny M, Guerfi A, Charest P, Rodrigues I, Mauger A, et al Safe and fast-charging Li-ion battery with long shelf life for power applications. Journal of Power Sources. 2011 apr;196(8):3949-3954. Available from: https://doi.org/10.1016/j.jpowsour.2010.11.093.

[41] Hoffman MG, Kintner-Meyer MC, Sadovsky A, DeSteese JG. Analysis Tools for Sizing and Placement of Energy Storage for Grid Applications - A Literature Review; 2010. Available from: https://doi.org/10. 2172/990130

[42] Bose S, Gayme DF, Topcu U, Chandy KM. Optimal placement of energy storage in the grid. IEEE. 2012 dec;Available from: https ://doi . org/ $10.1109 /$ cdc. 2012.6426113

[43] Fortenbacher P, Zellner M, Andersson G. Optimal sizing and placement of distributed storage in low voltage networks. IEEE. 2016 jun;Available from: https://doi.org/10.1109/pscc.2016.7540850.

[44] Grover-Silva E, Girard R, Kariniotakis G. Optimal sizing and placement of distribution grid connected battery systems through an SOCP optimal power flow algorithm. Applied Energy. 2018 jun;219:385-393. Available from: https://doi.org/10.1016/j . apenergy . 2017.09.008.

[45] Lu B, Stocks M, Blakers A, Anderson K. Geographic information system algorithms to locate prospective sites for pumped hydro energy storage. Applied Energy. 2018 jul;222:300-312. Available from: https://doi. org/10.1016/j . apenergy . 2018.03.177.

[46] Völker R, Kilper T, Schuldt F, von Maydell K, Agert C. Analysis of Stationary Electrical Storage Solutions for Residential Districts with High Photovoltaic Penetration. EU PVSEC. 2016;Available from: http://www.sunsniffer.de/images/imge_slide/ Next-Energy_paper_6DO.6.4.pdf. 